\title{
ALFABETIZAÇÃO EM TEMPOS DE PANDEMIA: PERSPECTIVAS PARA O ENSINO DA LÍNGUA MATERNA
}

\author{
Lucimar Gracia Ferreira ${ }^{*}$ \\ Lúcia Gracia Ferreira ${ }^{* *}$ \\ Giovana Cristina Zen ${ }^{* * *}$
}

RESUMO: Este artigo pontua aspectos desse novo momento que estamos vivenciando - da pandemia da COVID-19 - e a situação da educação nele, principalmente no que diz respeito a alfabetização, isto porque entendemos que alfabetizar é ensinar uma língua, a materna. Desse modo objetivou analisar as alternativas encontradas pelas professoras alfabetizadoras para oferecer as condições necessárias para a apropriação da leitura e da escrita no ERE. Para respondê-lo, realizamos uma pesquisa qualitativa e exploratória a partir da entrevista com três professoras alfabetizadoras de uma escola privada de um município baiano. Assim, foi instituído a adoção da educação remota para que o processo de escolarização continuasse a se concretizar devido a não recomendação de contato físico e foi orientado como esta poderia ocorrer. Neste estudo, refletimos sobre as limitações existentes no processo de alfabetizar remotamente, a partir de referencial bibliográfico existente e das narrativas das docentes que apontam dificuldades com as limitações do Ensino Remoto Emergencial para socialização, aspectos da leitura, escrita e contam, para concretização de ensino, principalmente, com os familiares dos alunos. Consideramos que o estudo em questão potencializa reflexões sobre o tema e pondera modos de saber-fazer dessa fase da escolarização tão específica.

PALAVRAS-CHAVE: Pandemia; Alfabetização; Práticas pedagógicas; Língua Materna.

\section{Introdução}

A pandemia pela COVID-19 adentrou as terras brasileiras e provocou mudanças bruscas em todas as esferas sociais. Ainda que tardias em alguns casos, várias medidas foram adotadas para conter a expansão do vírus. No âmbito educacional, o fechamento das escolas se impôs como uma das primeiras medidas emergenciais e com isto os sistemas de ensino tiveram que se reposicionar.

No dia 28 de abril, o Conselho Nacional de Educação (CNE) aprovou o Parecer CNE/CP 5/2020, que tratou da reorganização do calendário escolar, dispensando os estabelecimentos de ensino de cumprirem o mínimo de 200 dias letivos, desde que atendida a carga horária mínima anual de 800 horas. No dia 07 de julho, em complementação ao anterior, o CNE aprovou o Parecer CNE/CP n 11/2020 que dispõe sobre as "Orientações Educacionais para a Realização de Aulas e Atividades Pedagógicas Presenciais e Não

\footnotetext{
* Doutoranda em Educação pela Universidade Federal da Bahia (Ufba). Mestre em Educação pela Universidade Estadual do Sudoeste da Bahia (Uesb).

** Doutora em Educação pela Universidade Federal de São Carlos (UFSCar). Professora da Universidade Federal do Recôncavo da Bahia (UFRB). Professora do Programa de Pós-Graduação em Educação da Universidade Federal da Bahia. Realizou estágio pós-doutoral na Universidade Federal da Bahia (Ufba) e na Universidade Estadual do Sudoeste da Bahia (Uesb). Integrante do Grupo de Pesquisa e Estudos Pedagógicos/Uesb e Docência, Currículo e Formação/UFRB.

*** Doutora em Educação Universidade Federal da Bahia (Ufba). Professora da Faculdade de Educação da Ufba. Integra o Grupo de Pesquisa em Formação de Professores e atua como Vice líder do Grupo de Estudos e Pesquisas em Educação, Didática e Ludicidade.
} 
Presenciais no contexto da Pandemia", autorizando os sistemas de ensino a realizarem suas atividades na modalidade não presencial.

A partir de então se formaliza no país o Ensino Remoto Emergencial (ERE) que já estava em curso em várias instituições escolares, principalmente naquelas que são particulares. Os desafios para realização do ERE são incontáveis e várias foram as reflexões sobre a efetividade desta alternativa. No campo da alfabetização, a pergunta sobre as possibilidades de alfabetizar as crianças através do ensino remoto se impôs entre pais e educadores.

Diante desse cenário, assumimos como desafio problematizar as seguintes questões: como as práticas alfabetizadoras podem/devem acontecer no ERE? Quais as concepções de alfabetização orientam as práticas alfabetizadoras no ERE? Nesta perspectiva, este artigo tem como foco a discussão em torno da apropriação dos diferentes usos sociais da escrita no ERE, visto que a alfabetização pressupõe o ingresso nas culturas do escrito.

Diante do exposto, a filiação deste estudo à abordagem qualitativa de pesquisa se dá por entendermos que o fenômeno aqui estudado não pode ser conhecido através de experimentos, em que os resultados podem ser transcritos e representados por números. O que abordamos aqui é um fenômeno inédito no campo da educação, no qual professoras alfabetizadoras se veem diante do desafio de ensinar seus alunos a ler e a escrever durante o isolamento físico ocasionado pela pandemia da COVID-19.

Dessa forma, optamos por realizar uma pesquisa exploratória cujo propósito consiste em fornecer informações que possam ampliar a familiaridade dos pesquisadores com o tema em questão, oferecendo conceitos e hipóteses iniciais para estudos posteriores. Para tanto, foi utilizada a entrevista semiestruturada que orientou o diálogo com três professoras alfabetizadoras de uma instituição privada, que optou em realizar o ERE durante a pandemia da COVID-19. Esta escola se localiza num município da região do sudoeste da Bahia e é pertencente ao Território de Identidade 08.

Assim, cabe aqui apresentarmos a alfabetização como um processo pelo qual a criança passa a apropriar-se das culturas do escrito próprias da sua língua materna. Por ser aprendizagem dessa língua tão importante, necessária e específica é que buscamos problematizar sua constituição nesse contexto de educação remota.

A língua se faz pela interação. Desse modo, o ensino de uma língua deve abarcar aspectos relacionados aos contextos sociais e a diversidade neles existentes para promoção de reflexões nos participantes desse processo. Então, não cabe modos transmissionais de ensino, que apenas reproduz mecanicamente os conteúdos e se limita a conceitos e regras, mas 
deve viabilizar a construção de demandas que proporcione o desenvolvimento de possibilidades necessárias às práticas de leitura e escrita, como também a fala, a escuta e a socialização.

Desse modo, ratificamos - alfabetizar é ensinar uma língua -, aquela que o aluno, certamente, já fala e escuta, portanto, requer procedimentos de interação e de estratégias que possibilite ao aluno aprender a ler e escrever, ou seja, inserir nas culturas do escrito.

No processo de aprendizagem da língua materna a construção de uma relação entre linguagem oral e escrita é fundamental para que ocorra a alfabetização. Por isso, frisamos que a aprendizagem mecânica e descontextualizada socialmente não favorece a aprendizagem dessa língua que, inclusive não é privilégio de uma disciplina, pois a língua materna é instrumento de comunicação para todas as disciplinas e para acesso à cultura. Essa língua é componente essencial de um conjunto de práticas sociais e culturais.

Vale salientar que já superamos a ideia de alfabetização como processos de codificação e decodificação de um sistema, pois, reconhecemos que esta alfabetização é uma atividade também pedagógica e envolve o aprender-ensinar uma língua (que já usamos) e que, passará a ser apreendida no âmbito da leitura e escrita. Alfabetizar é, ainda, um processo de inclusão, esse, no mundo da linguagem.

Autores como Poersch (1990) e Pires, Ferreira e Lima (2010) nos chamam atenção para as especificidades presentes no processo de ensinar a língua materna que envolve não só o aluno, como também, e principalmente, o professor. Portanto, concebemos a alfabetização como um processo de desenvolvimento e aprendizagem de ler e escrever uma língua, que carrega em seu âmago uma gama de especificidades que acabam por exigir olhos diligentes e ouvidos atentos.

Diante do exposto, percebemos que alfabetizar, ou seja, ensinar a língua materna, do modo como a concebemos e acostumamos (presencial) já é demasiadamente difícil pelos minuciosos aspectos específicos existentes, portanto, realizar (tentar) esse mesmo trabalho a partir da educação remota é realizar um outro movimento, porque não é mais o mesmo processo de ensino. Muitas dessas especificidades podem não ser atendidas pelo contexto onde esse ensino se realiza (virtualmente na tela). Por isso, buscaremos, neste texto, refletir sobre o ensinar a língua materna no contex to remoto. Sendo assim, o objetivo desta pesquisa foi analisar as alternativas encontradas pelas professoras alfabetizadoras para oferecer as condições necessárias para a apropriação da leitura e da escrita no ERE. 


\section{Pandemia: que momento é esse?}

De repente, em meio a várias informações desencontradas sobre o número elevado de mortes em Wuhan na China, a Organização Mundial da Saúde $(\mathrm{OMS})^{1}$ declara, que há um surto de uma doença respiratória causada pelo novo coronavírus. Referenciando-o como uma "Emergência de Saúde Pública de Importância Internacional", ainda não se sabia o tamanho do problema que estava por vir. Esta declaração aconteceu no dia 30 de janeiro de 2020 e no dia 11 de março essa configuração muda de status. O surto da COVID-19, doença causada pelo vírus, é declarada como uma pandemia, se disseminando geograficamente. Segundo Ghebreyesus, falando pela OMS² (2020a, s/p):

[...], avaliamos que a COVID-19 pode ser caracterizada como uma pandemia. Pandemia não é uma palavra a ser usada de forma leviana ou descuidada. É uma palavra que, se mal utilizada, pode causar medo irracional ou aceitação injustificada de que a luta acabou, levando a sofrimento e morte desnecessários.

Quando foi declarado o contexto pandêmico, segundo o diretor-geral da OMS, Tedros Adhanom Ghebreyesus, já havia "mais de 118 mil casos em 114 países e 4,2 mil pessoas já haviam perdido a vida". De imediato, para conter a ameaça do vírus, seria necessário adotar medidas que envolviam governos e sociedade na elaboração de planos integrais e unificados para "prevenir infecções, salvar vidas e minimizar os impactos" (Diretor-geral da OMS, 2020).

Diante de tal situação, o mundo entrou em alerta porque a principal forma de combater o avanço do contágio era o isolamento físico, ou seja, as pessoas teriam que se isolar em seus lares e adotar medidas rígidas de higienização. Com este cenário, escolas foram fechadas, estabelecimentos comerciais não essenciais foram proibidos de funcionar e as pessoas não podiam mais circular pelas ruas. Situações restritivas necessárias, mas jamais pensadas pela humanidade.

No Brasil, o primeiro caso foi confirmado em 26 de fevereiro de 2020 (BRASIL, 2020c) em São Paulo. Conforme Macedo, Ornellas e Bomfim (2020, p. 3):

É necessário lembrar que em 1894, teve início em Hong Kong a terceira pandemia de peste bubônica, foram necessários cinco anos para que chegasse ao Brasil. Desta vez, bastaram alguns dias para a chegada dos primeiros casos suspeitos.

O surto da COVID-19 chegou rapidamente ao Brasil, com intenso processo de contágio. O vírus se espalhou inicialmente por São Paulo e, posteriormente, pelos outros Estados

\footnotetext{
${ }^{1}$ Informações da Organização Pan-Americana da Saúde (2020a).

2 Pronunciamento dado por Tedros Adhanom Ghebreyesus no briefing para a mídia sobre COVID-19, disponível no site da Organização Pan-Americana da Saúde (2020b).
} 
brasileiros. No dia 05 de março foram confirmados oito casos de COVID-19 no Brasil: "6 em São Paulo, 1 no Espírito Santo e 1 no Rio de Janeiro” (LINHA, 2020, s/p). Iniciou-se então uma corrida para conter o aumento de casos. Enquanto os países da Europa, Ásia, América, buscavam soluções plausíveis para reduzir a curva de contaminação, no Brasil, a situação foi ficando cada vez mais complicada.

Quando falamos em mortes, os números no Brasil deixaram explícitos que tudo que foi realizado para conter a proliferação do vírus não foi suficiente. Isto se deve ao impacto das desigualdades sociais, atrelados à falta de higiene e habitação da classe marginalizada, bem como das informações desencontradas, o que agravou ainda mais a crise sanitária no país. Além disso, contou com a negligência do atual governo que pouco se interessou em realizar um planejamento para conter o contágio. A capacidade de leitos de Unidade de Terapia Intensiva (UTI) e a quantidades de respiradores nos mais variados estados brasileiros não suportou o número de pessoas contaminadas, provocando o colapso do sistema de saúde pública em alguns lugares e, consequentemente, muitos cidadãos brasileiros morreram.

No início, os telejornais informavam que a COVID-19 não diferenciava ricos e pobres, negros e brancos. Apenas alertavam para maior incidência de óbito entre os mais velhos, o que não significa que os mais novos estavam imunes. O que se viu ao longo de 2020 foi que a COVID-19 colocou ainda mais em evidência a desigualdade social no nosso país. O contexto atual explicita as incertezas advindas da vulnerabilidade em que nossa sociedade se encontra, assim, como "a vida líquida é uma vida precária, vivida em condições de incertezas constantes" (BAUMAN, 2007, p. 8), assim também é a vida da população menos favorecidas.

As desigualdades sociais no Brasil, vem aumentando nas últimas décadas (NERI, 2019) e com o surto da COVID-19 este cenário se escancara, revelando o retrato das mazelas urbanas e seus diferentes grupos sociais, destacando o poder aquisitivo cultural, educacional, econômico e político da população brasileira. São relações de desigualdades sociais, estruturadas historicamente, desde o Brasil colônia, e que perduram até os dias atuais. "Tratar do avanço das desigualdades no contexto brasileiro é falar sobre o recrudescimento da pobreza no país, tornando mais evidentes as diferenças de renda, gênero, raça/etnia, bem como as diferenças regionais" (PITOMBEIRA; OLIVEIRA, 2020, p. 1700). Avanços esses que se agravaram com a pandemia, a população que já era vulnerável, está cada vez mais empobrecida e necessitada. O elevado nível das desigualdades sociais rompe com o que preconiza a Constituição Federal (BRASIL, 1988, p. 11) ao destacar como fundamentais alguns objetivos:

Art. $3^{\circ}$ III - erradicar a pobreza e a marginalização e reduzir as desigualdades sociais e regionais; IV-promover o bem de todos, sem preconceitos de origem, raça, sexo, cor, idade e quaisquer outras formas de discriminação (p. 11). 
Art. $5^{\circ}$ Todos são iguais perante a lei, sem distinção de qualquer natureza, garantindo-se aos brasileiros e aos estrangeiros residentes no País a inviolabilidade do direito à vida, à liberdade, à igualdade, à segurança e à propriedade, [...] (p. 13).

Os direitos dos cidadãos estão sendo violados bruscamente, são sujeitos marginalizados pela cor, sexo e poder aquisitivo. Os chamados "subalternos" são os que mais sofrem com os retrocessos e retiradas dos direitos sociais, refletindo diretamente na falta de saúde pública, no desemprego e na má qualidade da educação. Apesar do novo coronavírus não escolher público-alvo, aqueles que antes do contexto pandêmico já se encontravam em situação de vulnerabilidade são os que têm menos acesso às condições necessárias para lutar contra a COVID-19. Assim, "em vez da idade, classe social passa a definir quem morre de covid no país" (VESPA, 2020, s/p).

Neste cenário em que as desigualdades sociais estão ainda mais evidentes, os problemas educacionais, nos seus vários níveis e modalidades de ensino, também se explicitam. O que se tem observado são direcionamentos truncados que vão na contramão da oferta de condições adequadas para a aprendizagem, abandonando em meio à crise, professores e alunos à própria sorte.

Nunca se falou tanto em educação nos últimos meses. Segundo dados de pesquisa do Instituto DataSenado (CHAGAS, 2020) sobre a educação na pandemia, divulgada no dia 12 de agosto, entre os quase 56 milhões de alunos matriculados na educação básica e superior no Brasil, 35\% (19,5 milhões) tiveram as aulas suspensas devido à pandemia de COVID-19, enquanto que 58\% (32,4 milhões) passaram a ter aulas remotas. Na rede pública, 26\% dos alunos que estão tendo aulas online não possuem acesso à internet.

Desse modo, sem muitas alternativas, e com uma legislação permissiva, grande parte das escolas brasileiras passaram a funcionar a partir do Ensino Remoto Emergencial (ERE). O ERE foi a alternativa de manter as "escolas" funcionando, já que, por causa da pandemia, as aulas presenciais foram/estão suspensas em todos níveis educacionais do nosso país.

Sobre a ERE, Hodges, et al., (2020, p. 5-6), argumenta que:

$[\ldots]$ is a temporary shift of instructional delivery to an alternate delivery mode due to crisis circumstances. It involves the use of fully remote teaching solutions for instruction or education that would otherwise be delivered face-to-face or as blended or hybrid courses and that will return to that format once the crisis or emergency has abated. The primary objective in these circumstances is not to recreate a robust educational ecosystem but rather to provide temporary access to instruction and instructional supports in a manner that is quick to set up and is reliably available during an emergency or crisis $^{3}$.

\footnotetext{
${ }^{3}$ Tradução Livre: [...] é uma mudança temporária da entrega de instruções para um modo de entrega alternativo devido a circunstâncias de crise. Envolve o uso de soluções de ensino totalmente remotas para instrução ou educação que, de outra forma, seriam ministradas presencialmente ou como cursos combinados ou híbridos e
} 
Assim, os autores enfatizam que esta alternativa de ensino não é permanente, mas visa atender a um momento específico por um certo período de tempo, exigindo, nessas circunstâncias, que o planejamento educacional seja reelaborado conforme recursos e ferramentas disponíveis para realização do trabalho (HODGES; et al., 2020).

Destarte, a realização do trabalho docente vai requerer ainda mais dedicação, pois, para alguns professores manusear os artefatos tecnológicos necessários ao ensino remoto é uma situação totalmente nova e, neste momento tão delicado, é a única forma disponível para interagir com os alunos. Assim:

É nesse contexto que vem emergindo uma configuração do processo de ensinoaprendizagem denominada Educação Remota, isto é, práticas pedagógicas mediadas por plataformas digitais, como aplicativos com os conteúdos, tarefas, notificações e/ou plataformas síncronas e assíncronas [...] (ALVES, 2020, p. 352)

Além disso, o que tem se observado é a impossibilidade de uma transposição direta das práticas educativas realizadas na modalidade presencial para a não presencial, pois além do domínio dos artefatos tecnológicos, há um conjunto de saberes pedagógicos, específicos da modalidade online, que não é de domínio de todos os professores. Aos poucos, alunos, professores e gestores foram percebendo que realizar um ensino remoto é promover atividades via internet, em situações precárias, para dirimir os prejuízos causados pelo fechamento das escolas durante quase todo o ano letivo de 2020.

Ainda assim, os professores se desdobraram para encontrar soluções que pudessem envolver os alunos em um projeto educativo que fizesse algum sentido para eles, apesar de toda instabilidade que a pandemia da COVID-19 gerou em cada indivíduo. Entre eles, destacamos aqui os professores alfabetizadores, que assumem cotidianamente o compromisso político de assegurar aos seus alunos o direito de aprender a ler e a escrever na escola, e que durante o isolamento físico não se furtaram a esta responsabilidade.

\section{ALFABETIZAÇÃO EM TEMPOS DE PANDEMIA: PROPOSIÇÕES E ALTER- NATIVAS}

No contexto de uma crise como a da pandemia da COVID-19, o anseio pelos bons resultados na alfabetização gera oportunidades para que as grandes corporações educacionais proponham plataformas educacionais, que prometem soluções mágicas para a apropriação

que retornarão a esse formato assim que a crise ou emergência tiver diminuído. O objetivo principal nessas circunstâncias não é recriar um ecossistema educacional robusto, mas fornecer acesso temporário a instruções e apoio instrucional de uma maneira que seja rápida de configurar e esteja disponível de maneira confiável durante uma emergência ou crise. 
desse objeto tão valioso da nossa cultura que chamamos de escrita. Além disso, não faltam na internet sites e blogs que disponibilizam atividades e 'dicas' para alfabetizar as crianças em casa.

A partir deste cenário é perfeitamente plausível que alguns se questionem sobre a real necessidade da escola para ensinar as crianças a ler e a escrever. Será que estamos declarando a morte da escola? Será que a escola se tornou desnecessária para ensinar as crianças a ler e a escrever?

\begin{abstract}
Não podemos declarar a morte da escola! O computador não é uma escola! Ainda que seja assegurado o mínimo de interação nas tantas conferências que estão sendo realizadas pela escola, principalmente as particulares, o computador não é uma escola! Ainda que as tecnologias digitais estejam cada vez mais interessantes e atrativas, um computador não é uma escola! Nós precisamos da escola! Nós precisamos da escola para mostrar aos filhos de $44 \%$ da população brasileira, que esse objeto cultural que chamamos de escrita, nos transforma naquilo que nós somos [...]. Mais do que isso, a gente precisa da escola para compartilhar nossas ideias, para confrontar nossos valores, para confrontar nossas crenças. A gente precisa da escola, porque a gente precisa aprender a coisa pública. Porque a gente precisa assegurar as crianças o direito de estar entre seus pares [...]. Nós precisamos de uma escola com um currículo que respeite as crianças, que respeite os professores, que assegure o direito de aprender os diferentes usos desse objeto cultural tão valioso que chamamos de escrita. (ZEN, 2020, 42':04" a $\left.43^{\prime}: 47^{\prime \prime}\right)$
\end{abstract}

No contexto pandêmico, as discussões sobre o fechamento e a reabertura das escolas evidenciou a sua importância como instituição social. A escola não morreu, apenas a sua materialidade arquitetônica parou de funcionar. O que ela simboliza e representa continua evidente e as crianças seguem aprendendo, mesmo nas precárias condições do ERE. A modalidade online, quando realizada de forma responsável e comprometida, pode promover situações significativas de aprendizagem para os alunos, mas nunca poderá dar conta de todos os aspectos envolvidos na modalidade presencial. A cultura escolar, por exemplo, é única de cada escola e jamais poderá migrar para o online.

Entretanto, muitos questionamentos foram feitos enquanto as escolas estavam fechadas sobre a real possibilidade de alfabetizar as crianças no ensino remoto. O acompanhamento às crianças em processo de alfabetização também foi destaque no Parecer 5/2020, do Conselho Nacional de Educação (CNE), que trata da reorganização do calendário escolar e a possibilidade de atividades não presenciais para cumprimento de carga horária, com orientações referentes a todos os níveis de ensino. A maneira como a reorganização deve acontecer na Educação Básica, especificamente na alfabetização, é assim explicitado no referido parecer (2020a, p. 11):

Nesta etapa, existem dificuldades para acompanhar atividades on-line uma vez que as crianças do primeiro ciclo encontram-se em fase de alfabetização formal, sendo necessária supervisão de adulto para realização de atividades. No 
entanto, pode haver possibilidades de atividades pedagógicas não presenciais com as crianças desta etapa da educação básica, mesmo considerando a situação mais complexa nos anos iniciais. Aqui, as atividades devem ser mais estruturadas, para que se atinja a aquisição das habilidades básicas do ciclo de alfabetização. (grifos nossos)

O CNE reconhece a complexidade presente na alfabetização e por isso faz referência às dificuldades de realização e acompanhamento das atividades na modalidade online. Ainda, constata que a participação de um adulto é condição sine qua non para cumprimento desse processo. No ERE a supervisão do adulto para realização das atividades deixa de ser uma responsabilidade apenas dos professores e passa a ser compartilhada pelos familiares. A questão que aqui se apresenta é que as pessoas que convivem com a criança não possuem, e nem deveriam possui-la, formação adequada para acompanhá-la em seu processo de alfabetização. O que ocorre é que, em várias situações as crianças são abandonadas à própria sorte.

A Associação Brasileira de Alfabetização (ABALf), também se posicionou sobre ao ensino remoto destacando a importância da vida, em primeiro lugar, pois, no momento atual, "o que se tem de mais fundamental: o direito à vida" (2020, p. 1). A entidade também critica a manutenção do cumprimento das 800 horas, pois ressalta que isso "dá margem para a ampliação de propostas de atividades remotas, mesmo que as redes e os estudantes não tenham condições para tal" (ABALF, 2020, p. 1). Dessa forma, a responsabilidade da realização das atividades recairia sobre os professores e familiares de alunos. A ABALf destaca também que "a isso soma-se a etapa da alfabetização, que requer processo específico de interação constante entre professores e alunos, de modo que as ferramentas digitais apresentam limitação nesse sentido" (p. 1). Alfabetizar, exige atendimento de especificidades. Assim, a ABALf faz as seguintes considerações:

1) como o docente irá planejar um ensino de emergência/remoto para as mais
diversas realidades sociais de crianças, jovens, adultos e idosos, sobretudo àqueles
cujo acesso à tecnologia inexiste ou é precário? 2) Como planejar e ressignificar
as estratégias próprias de aulas presenciais, garantindo o acesso e a aprendizagem
de todos? Alfabetizar exige afetividade, interação entre pares, jogos, brincadeiras,
leituras, conversas, dramatizações, registros diversos, livros e outros materiais,
portanto, como garantir que essas atividades ocorram de modo à distância? 3)
Muitas dessas atividades, associadas às interações entre as crianças e entre as cri-
anças e os professores, requerem a observação, participação complementação e
intervenção dos professores, para se garantir e ampliar o processo de ensino e
aprendizagem. Nesse sentido, a aula remota é um padrão que não permite este
gerenciamento pedagógico e essa observação fundamental para se avançar no
processo de alfabetização. (ABALF, 2020, p. 1, 2)

A ABALf reafirma a ideia de que a alfabetização é um processo com especificidades próprias e que há todo um caminho a ser percorrido para que aconteça a aprendizagem da 
escrita e da leitura. Desse modo, não dá para tergiversar a alfabetização nesse contexto pandêmico. Ainda, para ABAIf (2020, p. 2):

\begin{abstract}
É lícito externar que mesmo reconhecendo nas tecnologias grandes possibilidades de construção de conhecimentos, ao considerar a realidade da maioria dos estudantes brasileiros da educação básica, esse formato de reposição/compensação remota/educação a distância acentuará a exclusão social, já que serão tratados de forma desigual os já desiguais. É justamente em relação a esse resultado que a ABAlf se contrapõe.
\end{abstract}

As desigualdades sociais foram acentuadas no cenário pandêmico e o que já era latente, ascendeu. No aspecto educacional, coadunamos com o posicionamento da ABALf ao destacar que generalizar as orientações, como proposto pelo Parecer 5/2020, é tratar “de forma desigual os já desiguais" (ABALF, 2020, p. 2).

Em conformidade com o que foi posto anteriormente, o Parecer 11/2020 (BRASIL, 2020b), reconhece as lacunas do processo de aprendizagem a partir das atividades não presenciais quando aponta que "as limitações na capacidade de implementar atividades não presenciais ao longo do período de isolamento social poderão afetar de modo desigual as oportunidades de aprendizagem dos alunos" (p. 2). Desse modo, a tendência é que os vulneráveis se tornem ainda mais vulneráveis e continuem sem acesso ao direito de aprendizagem. Diante desse cenário, com todas as dificuldades reconhecidas pelo próprio parecer, questiona-se se de fato será "possível alfabetizar na pandemia de forma remota"? Zen responde à pergunta e ressalta que:

\footnotetext{
Não seremos ingênuos. É preciso considerar que infelizmente nem todas as crianças têm em casa um acervo de coisas escritas que permitem essa interação. Nem todas as crianças têm uma estante com livros de literatura infantil à sua disposição. Nem todas as crianças têm computador ou internet. E isso escancara ainda mais a desigualdade social no nosso país. [...] Como pedir aos pais das classes menos favorecidas que compartilhem com seus filhos a "magia da leitura" quando nem eles a conhecem? Isso é perversão! E é justamente por este motivo que não podemos declarar a morte da escola. (2020, 37’:12”a 38':17’')
}

A autora provoca reflexões profundas que nos permite entender a complexidade em torno da alfabetização. Para compreender os diferentes usos sociais da escrita, a criança precisa participar de situações variadas que envolvem a escrita, ela precisa ter a oportunidade de participar de diversas práticas sociais de leitura e escrita. E para que isto aconteça, a criança precisa interagir, precisa dialogar, precisa manipular situações que envolvam a escrita e precisa ser acompanhada nesse processo. 


\title{
4. O que dizem as professoras sobre o desafio de alfabetizar no ensino remoto
}

A interação entre as crianças se configura como um grande desafio para o ERE. No processo de alfabetização, o confronto de ideias entre as crianças e as intervenções da professora são imprescindíveis para ajudar as crianças a avançarem em suas conceitualizações sobre a escrita. Por este motivo, questionamos as professoras participantes dessa pesquisa acerca das alternativas encontradas para concretização de práticas docentes no ERE.

\begin{abstract}
Estamos em uma busca e pesquisas diárias para podermos atender todas as expectativas e dificuldades das crianças, claro que não teremos o mesmo sucesso se fossem com as aulas presenciais. Na maioria das vezes estamos tendo devolutiva, mas os alunos não estão tendo uma rotina de estudos como antes das aulas remotas (P1).

Um desafio para alunos e professores, mas, não desistimos. E para que o objetivo seja alcançado, inúmeros recursos são usados nas propostas de atividades síncronas (durante as aulas na plataforma com a professora) e assíncronas (com o apoio dos familiares). Tudo para que os alunos participem e assimilem os conteúdos através de vivências significativas como: músicas, brincadeiras, figuras, construção de portfólio, escrita espontânea, leitura, contos, pesquisa e associações cotidianas promovem o engajamento do nosso trabalho (P2).
\end{abstract}

[...] E essas atividades são postadas em um grupo de WhatsApp dos pais, WhatsApp da Turma e vai todas as orientações de todas as aulas todo dia com as competências habilidades a serem desenvolvidas. Se tiver atividade impressa, nós mandamos anteriormente todas essas atividades. Elas são executadas na plataforma. Todos os alunos tiram suas dúvidas com a professora [...]. Nós estamos utilizando de estratégias visuais mesmo também estratégias que nos possibilitam a ludicidade, como os vídeos, a contação de história pelo próprio professor. Nós trabalhamos alguns jogos que nós mandamos anteriormente para os nossos alunos. Estamos explorando o livro didáticos e paradidáticos. Nós orientamos o trabalho, a criança em casa. [...]. Nós trabalhamos com questões abertas e também não abertas atividades também de múltipla escolha. Nós temos a devolutiva das atividades. Porque, por exemplo, quando nós colocamos ali e pedimos para que nós mandamos uma atividade de produção de texto, então nós orientamos toda essa produção de texto. Aí os pais mandam uma foto da produção de texto da criança. Individualmente, a gente faz essa correção e dá devolutiva no próprio WhatsApp, isso de forma privada, cada pai demanda e nós fazemos essa devolutiva (P3).

Nas narrativas das professoras é possível identificar um esforço hercúleo em oferecer boas situações de aprendizagem para as crianças. No entanto, há um reconhecimento dos limites que o ERE impõe. P1 anuncia inclusive que não será possível ter o mesmo sucesso das aulas presenciais. P2 explicita o uso de vários artefatos digitais para assegurar o "engajamento" e P3 relata as diversas estratégias didáticas utilizadas para acompanhar a produção dos alunos. As professoras explicitam ainda que as orientações aos familiares, para que os alunos realizem as atividades, também passaram a compor a organização do trabalho pedagógico.

O que se observa também na narrativa das três professoras é uma evidente tentativa em incorporar artefatos digitais, sem com isto renunciar à concepção de ensino que orientava a modalidade presencial. Expressões como "assimilem os conteúdos", "tiram suas dúvidas" 
e "a gente faz a correção" indicam uma concepção de ensino que primeiro explica como deve ser realizado e depois aplica-se o que aprendeu. Ainda que as professoras relatem a proposição de algumas práticas que valorizem a produção das crianças, como as escritas espontâneas, o que parece predominar ainda é uma concepção de ensino muito pautada na transmissão de conteúdos.

Isto indica que o problema não está apenas na impossibilidade do presencial e nos limites do ERE, mas na própria concepção de alfabetização que predomina nas salas de aula brasileiras. A pandemia da COVID-19 não escancarou as fragilidades dos professores, mas a inoperância das políticas públicas de formação de professores, que não conseguem propor transformações significativas na sala de aula.

$\mathrm{Na}$ contramão de uma perspectiva espontaneísta de alfabetização, na qual se considera que aprender a ler e a escrever é um processo natural, destaca-se a importância do professor como aquele que oferece boas situações de aprendizagem aos alunos, o que significa problematizar o que eles sabem sobre a escrita. Quando questionadas sobre o acompanhamento às aprendizagens das crianças, as professoras participantes da pesquisa comentaram:

Avaliar em um curto período é bem complicado, tento observar e registrar através da participação nas aulas, mas aqueles tímidos que pouco participam é mais complicado (P1).

É bem complicado avaliar nesse modo de ensino. Penso que para concretizar as práticas docentes precisamos orientar as famílias a criar uma rotina de estudos para suas crianças. Para isso, usamos os meios de comunicação disponíveis como nosso aliado nesse momento atípico e o trabalho através da construção de portfólio também facilita (P2).

\begin{abstract}
A leitura é uma prática muito contínua dentro da plataforma. Nós estamos sempre pedindo e orientando a leitura das crianças. [...]. Acontece também aquelas crianças que estão tendo muito mais dificuldades, que ainda não está com base alfabética muito boa, ou seja, que a sua consciência fonológica precisa ser ainda mais trabalhada na alfabetização. Isso eu digo porque é uma realidade da nossa turma. [...]. Eu vou percebendo as dificuldades fonológicas dela [...]. Nós tivemos resultados muito produtivos, embora desafiadores, assim também em relação à escrita. [...] já consigo ver e orientar em relação à escrita, em relação ao contorno da leitura, porque nós estamos ali, ele já inseriu a escrita cursiva no nível cinco. E eles vem trabalhando muito mais firmemente o traçado dessa no primeiro ano, então a gente consegue visualizando a imagem da atividade que nós colocamos de escrita ali (P3).
\end{abstract}

É consenso a dificuldade existente para realizar o trabalho docente na alfabetização no contexto do ensino remoto. Além de difícil, esse trabalho, tão específico, que carece de uma presença e de uma proximidade, é narrado como sendo complicado. No que tange ao acompanhamento das crianças, as professoras indicam a dificuldade de identificar o que sabem as crianças sobre a escrita neste contexto. P1 destaca a timidez dos alunos e P2 ressalta a 
necessidade de rotina de estudos no contexto familiar. P3 demonstra mais otimismo ao narrar as estratégias utilizadas para acompanhar os alunos. Entretanto, como nas narrativas anteriores, P3 explicita com maior veemência a sua concepção de alfabetização e mais uma vez indica que os desafios do atual momento não se restringem ao uso dos artefatos digitais. Os desafios em torno das práticas alfabetizadoras são anteriores ao fechamento das escolas por conta da pandemia da COVID-19.

Ao afirmar que "acontece também aquelas crianças que estão tendo muito mais dificuldades, que ainda não está com base alfabética muito boa, ou seja, que a sua consciência fonológica precisa ser ainda mais trabalhada na alfabetização”, P3 sugere que a consciência fonológica se configura como uma habilidade que precisa ser assegurada para que as crianças aprendam a ler a escrever. Desta forma, P3 corrobora com uma concepção de alfabetização que assume uma perspectiva que privilegia as propriedades fonológicas, em detrimento dos aspectos morfológicos, semânticos e culturais da língua escrita. De fato, a consciência fonológica é um aspecto importante do processo de alfabetização, mas ela não se constitui como uma habilidade que se desenvolve independentemente da escrita, nem tampouco se constitui como condição para aprender a ler e a escrever.

Por fim, as professoras falaram sobre suas perspectivas como alfabetizadoras para continuar alfabetizando no contexto remoto:

Fácil não é, algumas famílias têm se esforçado e dedicado ao máximo e tenho certeza que essas crianças não sentirão tantas dificuldades quanto as outras que não estão tendo a ajuda das famílias. Tempos difíceis, mas com toda certeza deixará muito aprendizado (P1).

Sei que a criança está em desenvolvimento e aprende o tempo todo, logo a alfabetização deve prosseguir em casa com o auxílio da família. Neste momento, a importância da participação dos pais que estão aprendendo lidar com esse novo modelo de ensino é indiscutível. Infelizmente não podemos contar com a colaboração de todos. Minhas perspectivas são as melhores possíveis, não posso mudar o que está acontecendo então, acredito que o trabalho com dedicação e compromisso sempre terá um resultado positivo (P2).

[...] então não está sendo muito difícil nem tanto. Imaginei que fosse muito mais difícil as trocas que a gente está tendo. A segurança das crianças aqui em relação a mim, a devolutiva, do que eles aprendem e também daquilo que eu consigo passar para eles. Eu percebo nitidamente o avanço de cada um deles. Eu percebo claramente quando aplicamos o assunto e que eu volto nesse assunto e que eles, em suas participações, demonstram a aprendizagem. É muito nítido. Uma outra coisa também, que nos pergunta em relação às famílias dos alunos e nos ajudam ou não. Eu vejo uma ajuda, uma colaboração muito grande das famílias desses meus alunos que estão no processo de alfabetização (P3).

Todas as professoras participantes da pesquisa indicam que se trata de um cenário difícil, mas há boas perspectivas, principalmente se continuarem contando com a ajuda dos familiares dos alunos. $\mathrm{O}$ resultado que se tem obtido nesse processo de alfabetizar no ensino 
remoto está diretamente relacionado ao apoio que as crianças têm recebido no contexto familiar. Assim, ao contrário da contradição posta pelo Parecer (5/2020), as famílias têm um papel fundamental na continuidade da escolarização dos alunos no contexto pandêmico. Apesar de todas as adversidades do momento, a parceria entre essas duas instituições sociais tem se fortalecido. Isto não significa esperar das famílias que assumam o papel da escola, mas que colaborem de forma efetiva para viabilizar as condições necessárias para que o vínculo da criança com a aprendizagem seja mantido, apesar do isolamento físico.

\section{Considerações finais}

Durante o isolamento físico, imposto ao longo de 2020 por conta da pandemia da COVID-19, a escola tem sido reinventada e diferentes modos de fazer escola tem surgido. Os educadores passaram a compreender que fazer escola não significa trancar um grupo de alunos em uma sala por um determinado tempo. Fazer escola implica relacionar-se com o outro, implica comprometer-se com o outro e com aquilo que ele pode e deve aprender.

A alfabetização é um processo pelo qual a criança passa para compreender os diferentes usos sociais da escrita. Ela realiza esse processo em diversos contextos sociais e as interações com os adultos que sabem ler e escrever é fundamental para que este processo aconteça. $\mathrm{Na}$ escola a criança tem a oportunidade de participar de situações planejadas com o propósito de colocar em questão o que sabem para avançar em suas conceitualizações sobre a escrita. Apesar de todas as elaborações que a criança realiza fora da escola, as intervenções que acontecem no contexto escolar são fundamentais para assegurar a todas as crianças o direito de apropriar-se das culturas do escrito.

O ERE impõe limites e, apesar de se configurar na única alternativa possível no contexto pandêmico, não se constitui na melhor alternativa para a alfabetização. O ERE assegura a manutenção do vínculo das crianças com o contexto escolar, mas cerceia as possibilidades de participação em diversas práticas sociais de leitura e escrita que envolvem a participação do coletivo.

Dessa forma, propor situações de leitura e escrita que de fato façam sentido para as crianças tem sido o maior desafio para os professores alfabetizadores que estão trabalhando no ERE. Para dirimir as limitações que a distância física impõe, os professores estão sendo convocados a mudar suas práticas pedagógicas, adotando novas metodologias e manuseando artefatos digitais até então desconhecidos. Tudo isso sem uma política de formação de professores que assegure as condições necessárias para essa transformação. 
Os profissionais das instituições de ensino precisam sim se reinventar, reinventar a docência em meio a essa mudança de cenário. O que é preocupante nesse momento são as condições em que essa reinvenção precisa acontecer. A aprendizagem dos alunos tende a se dar, rodeada por um contexto de crise, de perdas e de incertezas. É nesse contexto que se impõe que a alfabetização aconteça.

\title{
LITERACY IN PANDEMIC TIMES: PERSPECTIVES FOR TEACHING THE MATERNAL LANGUAGE
}

\begin{abstract}
This article points out aspects of this new moment that we are experiencing - the pandemic of COVID-19 - and the situation of education in it, mainly with regard to literacy, this is because we understand that literacy is teaching a language, the mother tongue. Thus, it aimed to analyze the alternatives found by literacy teachers to offer the necessary conditions for the appropriation of reading and writing in the ERE. To answer it, we conducted a qualitative and exploratory research based on an interview with three literacy teachers from a private school in a municipality in Bahia. Thus, the adoption of remote education was instituted so that the schooling process would continue to materialize due to the non-recommendation of physical contact and was guided as to how it could occur. In this study, we reflect on the limitations that exist in the process of remotely teaching literacy, based on the existing bibliographic reference and the narratives of teachers who point out difficulties with the limitations of Emergency Remote Teaching for socialization, aspects of reading, writing and counting, for teaching, mainly, with the students' relatives. We consider that the study in question enhances reflections on the theme and ponders ways of knowing how to do this phase of schooling so specific.
\end{abstract}

KEYWORDS: Pandemic; Literacy; Pedagogical practices; Mother tongue.

\section{REFERÊNCIAS}

ABALF, Associação Brasileira de Alfabetização. Posicionamento da ABALf sobre a reposição de aulas remotas na Educação Básica. Ofício no 16/99 - GOE - APLO, 16/04/2020. Disponível em: https:/ /28473cf1-9f63-40b0-b146-f3b3c65a8b23.filesusr.com/ugd/64d1da_ 02d84c489f924895a8ceb7ffc60fe062.pdf. Acesso em: 06 ago. 2020.

ALVES, Lynn. Educação Remota: entre a ilusão e a realidade. Revista Interfaces Científicas, Aracajú, v. 8, n. 3, p. 348-365, 2020. Disponível em: https://periodicos.set.edu.br/educacao/article/view/9251/4047. DOI: https://doi.org/10.17564/2316-3828.2020v8n3p348365. Acesso em: 09 ago. 2020.

BRASIL. Ministério da Educação. Conselho Nacional de Educação. Parecer CNE/CP 5, de 28 de abril de 2020. Reorganização do Calendário Escolar e da possibilidade de cômputo de atividades não presenciais para fins de cumprimento da carga horária mínima anual, em razão da Pandemia da COVID-19. Brasília: DF, 2020a. D.O.U. de 01/06/2020, Seção 1, Pág. 32. 2020a. Disponível em: Acesso em: 1 ago. 2020. http://portal.mec.gov.br/index.php?option $=$ com_docman\&view $=$ download\&alias $=145011-$ pcp005-20\&category_slug $=$ marco-2020-pdf\&Itemid $=30192$.

BRASIL. Ministério da Educação. Conselho Nacional de Educação. Parecer CNE/CP 11, de 07 de julho de 2020. Orientações Educacionais para a Realização de Aulas e Atividades Pedagógicas Presenciais e Não Presenciais no contexto da Pandemia. Brasília: DF, 2020b. Disponível em: http://portal.mec.gov.br/index.php?option=com_docman\&view $=$ download\&alias=148391-pcp011-20\&category_slug=julho-2020-pdf\&Itemid=30192. Acesso em: 28 ago. 2020. 
BRASIL. Ministério da Saúde. Brasil confirma primeiro caso da doença. 26/02/2020. Disponível em: https://www.saude.gov.br/noticias/agencia-saude/46435-brasil-confirma-primeirocaso-de-novo-coronavirus. Acesso em: 19 mar. 2020. 2020c.

BRASIL. Presidência da República. Medida Provisória 934, de 01 de abril de 2020. Estabelece normas excepcionais sobre o ano letivo da educação básica e do ensino superior decorrentes das medidas para enfrentamento da situação de emergência de saúde pública de que trata a Lei no 13.979, de 6 de fevereiro de 2020. 2020d. Disponível em: http:/ /www.planalto.gov.br/ccivil_03/_ato2019-2022/2020/mpv/mpv934.htm.

Acesso em: 23 jul. 2020.

BRASIL. Constituição da República Federativa do Brasil: promulgada em 5 de outubro de 1988. Brasília, 1988. Disponível em:

http://www.planalto.gov.br/ccivil_03/constituicao/constituicao.htm. Acesso em: 08 ago. 2019.

CHAGAS, Elisa. DataSenado: quase 20 milhões de alunos deixaram de ter aulas durante pandemia. 12/08/2020. Disponível em: https://www12.senado.leg.br/noticias/materias/2020 /08/12/datasenado-quase-20-milhoes-de-alunos-deixaram-de-ter-aulas-durante-pandemia. Acesso em: 16 set. 2020.

FERREIRO, Emília.; TEBEROSKY, Ana. A psicogênese da língua escrita. Porto Alegre: Artmed, 1999.

FERREIRO, Emília. A Alfabetização e as Novas Tecnologias. Disponível em: http://blog.pat.educacao.ba.gov.br/blog/2015/06/a-alfabetizacao-e-as-novas-tecnologiaspor-emilia-ferreiro/. Acesso em: 11 ago. 2020.

G1. China tem mais de 78 mil casos de Covid-19 e anuncia quarentena para turistas de países atingidos. 26/02/2020. Disponível em: https://g1.globo.com/ciencia-e-saude/noticia/2020/02/26/china-tem-mais-de-78-mil-casos-de-covid-19.ghtml. Acesso em: 29 jul. 2020 .

HODGES, Charles.; MOORE, Stephanie; LOCKEE, Barb; TRUST, Torrey; Bond, Aaron. The Difference Between Emergency Remote Teaching and Online Learning, Revisão EDUCAUSE, 2020. Disponível em: https://er.educause.edu/articles/2020/3/the-differencebetween-emergency-remote-teaching-and-online-learning\#fn1. Acesso em: 12 mai. 2020.

LINHA do tempo do Coronavírus no Brasil. Disponível em: https://www.sanarmed.com/linha-do-tempo-do-coronavirus-no-brasil_Acesso em: 29 jul. 2020.

MACEDO, Yuri Miguel; ORNELLAS, Joaquim Lemos; BOMFIM, Helder Freitas. COVID-19 no Brasil: o que se espera para população subalternizada? Revista Encantar - Educação, cultura e sociedade. Bom Jesus da Lapa, v. 2, p. 1-10, jan./dez., 2020. Disponível em: https://revistas.uneb.br/index.php/encantar/article/view/8189. Acesso em: 15 ago. 2020.

PIRES, Maria das Graças Porto.; FERREIRA, Lúcia Gracia; LIMA, Daniel Fernandes. Alfabetização, professor alfabetizador e prática pedagógica. Revista Letra Magna. Ano 06, n. 13, $2^{\circ}$ Semestre de 2010. Disponível em: http://www.letramagna.com/Artigo10_13.pdf.

Acesso em: 17 ago. 2020.

PITOMBEIRA, Delane Felinto; OLIVEIRA, Lucia Conde de. Pobreza e desigualdades sociais: tensões entre direitos, austeridade e suas implicações na atenção primária. Ciência \& Saúde Coletiva, 25(5): 1699-1708, 2020. Disponível em: https://www.scielo.br/pdf/csc/v25n5/1413-8123-csc-25-05-1699.pdf. Acesso em: 15 ago. 2020. 
POERSCH, José Marcelino. Pode-se alfabetizar sem conhecimentos de lingüísticas? TASCA, Maria; POERSCH, José Marcelino (Orgs.). Suportes Lingüisticos para a alfabetização. 2 ed. Porto Alegre: Sagra, 1990. p. 9-41.

ZEN, Giovana Cristina. A relação entre currículo e alfabetização no periodo da pandemia da Covid19. Ciclos de debates/live. Instituto Chapada - ICEP, 06 de junho, 2020. Disponível em: https://www.facebook.com/watch/live/?v=337857267200509\&ref=watch_permalink. Acesso em: 25 ago. 2020.

ZEN, Giovana Cristina; MOLINARI, Maria Cláudia; NASCIMENTO, Aline Carvalho. As práticas cotidianas de leitura e escrita na escola como um direito da infância. Revista Práxis Educacional, Vitória da Conquista-Bahia, v. 16, n. 41. p. 255-277, Edição Especial, 2020. Disponível em: http://periodicos2.uesb.br/index.php/praxis/article/view/7263. Acesso em: 23 set. 2020.

NERI, Marcelo C. A escalada da desigualdade: qual foi o impacto da crise sobre a distribuição de renda e a Pobreza? Rio de Janeiro: RJ. FGV Social. Agosto/2019. Disponível em:

https://www.cps.fgv.br/cps/bd/docs/A-Escalada-da-Desigualdade-Marcelo-Neri-FGVSocial.pdf.Acesso em: 03 jun. 2020.

ORGANIZAÇÃO Pan-Americana da Saúde (OPAS). Histórico. Disponível em: https: / / www.paho.org/bra/index.php?option=com_content\&view $=$ article\&id $=6101:$ :covid19\&Itemid $=875$. Acesso em: 03 jun. 2020. 2020a.

ORGANIZAÇÃO Pan-Americana da Saúde (OPAS). OMS afirma que COVID-19 é agora caracterizada como pandemia. Disponível em: https://www.paho.org/bra/index.php?option $=$ com_content\&view $=$ article\&id $=6120$ :oms-afirma-que-covid-19-e-agora-caracterizada-como-pandemia\&Itemid=812. Acesso em: 03 jun. 2020. 2020b.

PORTUGAL é o único país na "lista negra" britânica que está abaixo da média europeia de casos: o coronavírus cá e no mundo (em gráficos). 14/08/2020. Disponível em: https://expresso.pt/coronavirus/2020-08-14-Portugal-e-o-unico-pais-na-lista-negra-britanica-queesta-abaixo-da-media-europeia-de-casos-o-coronavirus-ca-e-no-mundo--em-graficos-. Acesso em: 25 ago. 2020.

RELATÓRIO DE SITUAÇÃO - 1. 03/03/2020. Disponível em: https://covid19.minsaude.pt/wp-content/uploads/2020/03/Relato\%CC $\% 81$ rio-de-Situac $\%$ CC $\%$ A7a $\%$ CC $\% 83 o-1 . p d f$. Acesso em: 22 jun. 2020.

VESPA, Talyta. Em vez da idade, classe social passa a definir quem morre de covid no pais. UOL, São Paulo. 06/05/2020. Disponível em: https://noticias.uol.com.br/saude/ultimas-noticias/redacao/2020/05/06/no-brasil-covid-19-nao-mata-por-idade-mas-por-endereco-sugere-estudo.htm . Acesso em: 29 jul. 2020.

Recebido em: 30/09/2020.

Aprovado em: 26/01/2021. 